\title{
SURGICAL TREATMENT OF HEMORRHOIDS: A CRITICAL APPRAISAL OF THE CURRENT OPTIONS
}

\author{
Tratamento cirúrgico das hemorroidas: uma análise crítica das atuais opções
}

\author{
Marlise Mello CERATO ${ }^{1}$, Nilo Luiz CERATO ${ }^{1}$, Patrícia PASSOS ${ }^{1}$, Alberto TREIGUER ${ }^{1}$, Daniel C. DAMIN ${ }^{2}$
}

\begin{abstract}
From the ${ }^{1}$ Divisão de Coloproctologia, Hospital Ernesto Dornelles, Porto Alegre, RS (Division of Coloproctology, Ernesto Dornelles Hospital, Porto Alegre, RS); 2Divisão de Coloproctologia, Hospital das Clínicas de Porto Alegre and Departamento de Cirurgia, Universidade Federal do Rio Grande do Sul, Porto Alegre, RS (Division of Coloproctology, Hospital de Clínicas de Porto Alegre and Department of Surgery, Federal University of Rio Grande do Sul), Porto Alegre, RS, Brazil.
\end{abstract}

HEADINGS - Hemorrhoids. Hemorrhoidectomy. Surgical procedures. Pain. Recurrence. Bleeding and prolapsed hemorrhoids.
RESUMO - Introdução: O tratamento cirúrgico da doença hemorroidária é ainda um dilema. Novas técnicas foram desenvolvidas levando à taxa menor de dor pósoperatória, contudo com maior chance de recorrência. Objetivo: Revisar as indicações atuais de tratamento cirúrgico da doença hemorroidária, assim como os resultados e complicações das técnicas hoje utilizadas. Método: Foi realizada revisão sistemática das publicações sobre as opções de tratamento cirúrgico da doença hemorroidária, utilizando dados da Medline/Pubmed, Cochrane e UpToDate, até dezembro de 2012. Resultados: As opções de tratamento cirúrgico disponíveis são procedimento para correção de prolapso (PPH), dearterialização hemorroidária trans-anal (THD) e técnicas convencionais de hemorroidectomia. As técnicas excisionais têm resultados semelhantes quanto à dor, tempo de retorno às atividades e índice de complicações. O PPH e o THD apresentam menos dor pós-operatória, menor taxa de complicações, porém têm maior recidiva pós-operatória. Conclusão: As técnicas de cirurgia convencional têm melhores resultados a longo prazo. Apesar de bons resultados no período pós-operatório imediato, PPH e THD não apresentam resultados consistentes a longo prazo.

\section{Correspondence:}

Marlise Mello Cerato Michaelsen

E-mail: mcerato@hotmail.com

Financial source: none

Conflicts of interest: none

Received for publication: 30/05/2013

Accepted for publication: 28/11/2013

DESCRITORES - Hemorróidas. Hemorroidectomia. Procedimentos cirúrgicos. Dor. Recorrência. Sangramento e hemorróidas prolapsadas.
ABSTRACT - Introduction: Surgical treatment of hemorrhoids is still a dilemma. New techniques have been developed leading to a lower rate of postoperative pain; however, they are associated with a greater likelihood of recurrence. Aim: To review current indications as well as the results and complications of the main techniques currently used in the surgical treatment of hemorrhoidal disease. Methods: A systematic search of the published data on the options for treatment of hemorrhoids up to December 2012 was conducted using Medline/PubMed, Cochrane, and UpToDate. Results: Currently available surgical treatment options include procedure for prolapse and hemorrhoids (PPH), transanal hemorrhoidal dearterialization (THD), and conventional hemorrhoidectomy techniques. Excisional techniques showed similar results regarding pain, time to return to normal activities, and complication rates. PPH and THD were associated with less postoperative pain and lower complication rates; however, both had higher postoperative recurrence rates. Conclusion: Conventional surgical techniques yield better long-term results. Despite good results in the immediate postoperative period, PPH and THD have not shown consistent long-term favorable results.

INTRODUCTION

$\mathrm{H}$ emorrhoidal disease is a common disorder, affecting $4 \%$ of the world population. The most widely accepted theory attributes this disorder to the prolapse of the anal cushions. Hemorrhoids are not varicose veins, but rather vascular cushions composed of fibroelastic tissue, muscle fibers, and vascular plexuses with arteriovenous anastomoses. Hemorrhoids may be internal, external or mixed. Internal hemorrhoids are classified by the degree of prolapse of the anal canal. External may be classified as acute (hemorrhoidal thrombosis) or chronic (anal skin tags).

Patients with hemorrhoids often seek treatment because of painless bleeding, prolapse, pain associated with hemorrhoidal thrombosis or itching. Conservative medical treatment, which is initially indicated in most cases, includes increased dietary fiber and fluid intake and use of topical agents. When there is no initial clinical improvement, more invasive treatment methods 
are warranted, such as rubber band ligation, infrared coagulation and sclerotherapy.

Surgical treatment is generally reserved for those patients who have failed to respond to conservative measures, about $5-10 \%$ of patients. Surgical treatment is the initial option in the management of symptomatic third- or fourth-degree hemorrhoids, or in patients with acute hemorrhoids that have not improved with other therapies ${ }^{24}$.

Hemorrhoidectomy is considered the gold standard, and Milligan-Morgan's and Ferguson's procedures are the most widely used techniques throughout the world. Although these techniques have yielded excellent results and low complication rates, they are usually associated with postoperative pain ${ }^{24,26}$. In order to reduce pain, new procedures have been introduced, including the procedure for prolapse and hemorrhoids (PPH) and Doppler-guided hemorrhoidal artery ligation.

This study aimed to review current indications as well as the results and complications of the main techniques currently used in the surgical treatment of hemorrhoidal disease.

\section{METHODS}

A systematic literature search was conducted using Medline/PubMed (http://www.ncbi.nlm.nih.gov/ pubmed) and Cochrane (http://www2.cochrane.org/ reviews/). The search included, but was not limited to, review articles, meta-analyses, clinical trials, multicenter studies, guidelines, and guideline projects, among others, published in English, Portuguese, and Spanish. There were no restrictions on publication time range. The following keywords were used: hemorrhoids, hemorrhoidectomy, surgical procedures, pain, recurrence, bleeding and prolapsed hemorrhoids. UpToDate (http:// www.uptodateonline.com/online/index/do), Topic 1382, version 10.0/2012, was also consulted.

\section{Conventional surgical treatment}

Conventional surgery basically involves the excision of the piles. In a meta-analysis of 18 prospective randomized trials comparing conventional surgery with outpatient procedures, including rubber band ligation, sclerotherapy, and infrared coagulation, surgery was found to be the most effective treatment modality. Open (MilliganMorgan) and closed (Ferguson) hemorrhoidectomy are the most commonly used techniques ${ }^{13}$. Complications associated with these procedures include urinary retention, postoperative bleeding, pain, anal stenosis, and incontinence ${ }^{3}$.

Although hemorrhoidectomy can be performed using a common scalpel, scissors, mono or bipolar modes of electrosurgery, ultrasonic scalpel or laser, no clear advantage of one method over the other has been demonstrated $^{15}$. In a recent Cochrane Database review, evaluating 12 studies with 1,142 patients, the use of bipolar energy was found to shorten the procedure time and produce less postoperative pain when compared to conventional surgery ${ }^{18}$.

\section{Closed hemorrhoidectomy}

Is the most commonly used surgical technique. An elliptical incision is made in the external hemorrhoidal tissue extending proximally through the dentate line to the upper limit of hemorrhoids. One should take care to make a narrow ellipse and remove only the redundant anoderm and hemorrhoidal tissue. The wound is closed with continuous absorbable suture. Usually three piles are excised. This technique is effective in $95 \%$ of cases, and surgical wound infection is extremely rare ${ }^{5}$.

\section{Open hemorrhoidectomy}

The open technique is globally widespread and preferred by many surgeons. A study comparing the open technique versus a modified closed (semi-open) hemorrhoidectomy showed that such modification was associated with faster healing and fewer postoperative complications $^{26}$. Generally, complications following conventional hemorrhoidectomy procedures include urinary retention (2-36\%), bleeding (0.03-6\%), anal stenosis $(0-6 \%)$, infection (0.5-5\%), and incontinence (2$12 \%)^{26}$.

Lateral internal sphincterotomy with
hemorrhoidectomy
Lateral internal sphincterotomy should not be routinely combined with hemorrhoidectomy, because this combination may lead to major complications, such as varying degrees of anal incontinence, without significantly reducing postoperative pain ${ }^{24}$. In selected cases of patients with preoperative manometric findings of increased resting sphincter pressure, lateral internal sphincterotomy appears to be safe and not associated with a significant increase in postoperative morbidity ${ }^{6}$.

\section{Hemorrhoidectomy using energy sources}

Although the use of an electric scalpel may shorten the procedure time and reduce blood loss during surgery, it offers no advantage regarding pain, healing time, and early or late complications. ${ }^{10}$ Likewise, the use of an ultrasonic scalpel has also shown no advantage over the electric scalpe ${ }^{28}$.

Open hemorrhoidectomy using a bipolar electrosurgical scalpel is associated with the need for fewer postoperative analgesics, faster wound healing and more rapid return to work when compared to the same procedure using an electric scalpel. However, it offers no advantage regarding postoperative pain, patient satisfaction, disease recurrence, or incidence of postoperative complications ${ }^{14,16}$.

A recent meta-analysis evaluated the results of 10

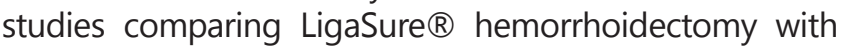
the conventional technique. According to the authors, the 
use of LigaSure ${ }^{\circledR}$ showed statistically superior results in several parameters, including shorter operative time, less postoperative pain, less urinary retention, and more rapid return to normal activities. However, there is considerable heterogeneity in the studies analyzed. Moreover, there are no studies reporting long-term results of patients who were operated on using LigaSure ${ }^{\circledR 15}$. The use of laser, proposed in the 1990s, has failed to show advantages over conventional surgery, being rarely used today. ${ }^{28}$

\section{Non-excisional surgical techniques}

\section{PPH (stapled hemorrhoidopexy)}

New technique using a stapler (stapled hemorrhoidectomy), which is also known as PPH. This technique uses a specific (circular) stapler to excise a circumferential ring of mucosa above the dentate line. The main characteristic of this procedure is the absence of external surgical wounds, which makes this surgery potentially less painful than the conventional procedure.

$\mathrm{PPH}$ is indicated for patients with second-degree hemorrhoids, with recurrent bleeding, who have failed to respond to non-surgical methods and in the management of third- or fourth-degree hemorrhoids, as long as they are not too bulky (i.e., they do not involve the entire anal circumference). The potential benefits of PPH include shorter operative time, less postoperative pain, less urinary retention, and more rapid return to normal activities. Despite these postoperative advantages, long-term results are insufficient, particularly regarding residual skin tags and recurrent prolapse ${ }^{3}$. Another issue is the large number of complications that have been reported with $\mathrm{PPH}$, such as rectal perforation, pelvic sepsis, rectovaginal fistula, intra-abdominal bleeding, and Fournier's gangrene, which have required exploratory laparotomy and/or diversion, 2,4,17,20,23,31. Some authors reported symptoms of severe pain and fecal urgency that persisted for up to 15 months after PPH, which was probably caused by purse-string suture placed too close to the dentate line and impingement of the staple line on the sensitive area of the anoderm. Placement of the purse-string suture high or low, with inaccurate depth, may lead to serious complications ${ }^{10}$.

\section{$P P H$ versus conventional technique}

Three systematic reviews have concluded that stapled hemorrhoidopexy is less effective than the conventional procedure and is associated with a higher incidence of recurrence and prolapse. The studies have also shown a higher rate of further surgery and tenesmus when using the stapler. Conversely, hemorrhoidopexy with $\mathrm{PPH}$ is associated with less postoperative pain, shorter operative time, shorter hospital stay, and early return to normal activities $7,13,19$.

A recent meta-analysis comparing hemorrhoidopexy with conventional surgery showed a higher recurrence rate among patients who had undergone $\mathrm{PPH}^{19}$. However, a 2007 review, which evaluated six randomized trials with 628 patients followed up for one year or more after hemorrhoid surgery, showed no differences between conventional hemorrhoidectomy and hemorrhoidopexy in terms of pain, itching and urgency, with greater recurrence associated with $\mathrm{PPH}^{19}$. Although hemorrhoidopexy is associated with a large number of complications, in general, the overall index is similar to that of conventional surgery. A meta-analysis involving 2,000 patients found a complication rate of $20 \%$ for $\mathrm{PPH}$ and $25 \%$ for conventional surgery ${ }^{29}$.

\section{Transanal hemorrhoidal dearterialization (THD)}

Faced with the dilemma of surgical treatment of hemorrhoids, Morinaga et al. ${ }^{22}$ developed in 1995 a new therapeutic option known as THD. The procedure uses a kit with an anoscope that reaches the upper portion of the lower rectum, where a Doppler device locates the terminal branches of the hemorrhoidal arteries $(6-7 \mathrm{~cm}$ from the anal margin) at the 1, 3, 5, 7, 9, and 11 o'clock positions of the rectal circumference. These vessels are ligated in a cranial-caudal direction up to the lower limit of the Doppler signal, $2 \mathrm{~cm}$ from the anal margin, above the dentate line. The lower portion of the suture ligation is tied to the upper portion performing a mucopexy, with prolapse reduction. The procedure may be indicated for patients with bleeding second-, third- or fourth-degree hemorrhoids, with or without hemorrhoidal prolapse, who have failed to respond to non-surgical procedures.

A study evaluated 100 patients undergoing THD and reported no cases of death within 24 hours of surgery; transient hemorrhoidal thrombosis occurred in two (2\%) cases and urinary retention in five (5\%) patients. No patient had fecal incontinence. Ten (10\%) patients complained of some degree of pain at defecation. Of these, only five required analgesics for more than three days, but none of them used medication for over 10 days. At 30-day followup, no patient complained of pain. At 3-month follow-up, all patients reported an improvement in symptoms. None had chronic pain. Three patients reported occasional bleeding after defecation, less than once per month, and one of these patients required further rubber band ligation. Eight patients experienced residual prolapse, and five of them required further mucopexy ${ }^{22}$.

A systematic review including 1,996 patients showed a recurrence rate of $9 \%$ for prolapse, $8 \%$ for bleeding, and $5 \%$ for pain at defecation. The authors reported a higher recurrence rate for patients with fourthdegree hemorrhoids, recommending that the technique should be used preferably for second- and third-degree hemorrhoids?.

THD for fourth-degree hemorrhoids was performed in 35 patients in another study. There were no intraoperative complications. Postoperative complications included hemorrhoidal thrombosis in three $(8.6 \%)$ patients (one requiring surgery) and bleeding in two (5.7\%) patients (one requiring surgical hemostasis). Five (14.3\%) patients had urinary retention requiring catheterization. At a median follow-up of 10 months, symptoms resolved or greatly improved in 33 (94\%) patients. Nine (25.7\%) 
patients reported irregular bleeding, three (8.6\%) mild anal pain, four (11.4\%) mild anal burning, and four (11.4\%) tenesmus. Ten patients (28.6\%) experienced some degree of residual prolapse, significant only in two (5.7\%), who required further surgery. No patient had stenosis or incontinence. The authors concluded that THD is a safe and effective treatment for fourth-degree hemorrhoids, and that persisting symptoms, when present, are mostly transient and occasional21

\section{THD versus pexy procedures without Doppler transducer \\ A single-blinded randomized clinical trial compared} THD and hemorrhoidal artery ligation, without mucopexy ${ }^{11}$. Procedures were performed in 35 patients without use of the Doppler transducer and in 38 with the Doppler transducer. The groups had similar preoperative characteristics and all patients had second- or thirddegree hemorrhoids. The number of hemorrhoidal artery ligation procedures was the same in both groups. Postoperative pain was also similar in both groups. Time to return to normal activities was 9.8 days on average in the non-Doppler group and 7.7 days in the Doppler group, without statistical significance. In both groups, an improvement was observed with regard to preoperative complaints of pain, bleeding, prolapse, and problems with defecation. The non-Doppler group, however, showed greater improvement in hemorrhoidal prolapse. Patients in the non-Doppler group showed no complications. In the Doppler group, three patients had pain and persistent bleeding. After six months, patients in the non-Doppler group required no further procedures. In the Doppler group, two hemorrhoidectomies and three rubber band ligation procedures were performed. Regarding patient satisfaction, those undergoing the procedure without use of the Doppler transducer were more satisfied with the outcomes both at six weeks and six months after surgery. These data suggest that the benefits of THD may not be associated with the precise location of the vessels using the Doppler transducer. One hypothesis is that, due to several ligations, the pressure in the arterial microcirculation of the corpora cavernosa decreases, reducing the volume of hemorrhoids and relieving symptoms.

\section{THD plus mucopexy}

A recent study proposed the use of THD combined with rectoanal repair modified for third- and fourthdegree hemorrhoids. The technique recommends, after Doppler-guided hemorrhoidal artery ligation, performing mucopexy of the prolapsed hemorrhoidal tissue, restoring its anatomical and physiological position ${ }^{30}$. Twenty patients were treated and evaluated three and 12 months after the procedure by rectal examination, anorectal manometry, and quality of life questionnaires. There was one case of postoperative bleeding, which was successfully managed with sterile anal tamponade. After three months, there were five cases of minor residual prolapse. Three of these patients reported painful defecation or itching. Regarding anorectal manometry assessment, basal anal pressure levels were lower than before the procedure, and a less significant decrease was observed in squeeze anal pressure levels. No patient complained of incontinence. Regarding satisfaction as measured with the quality of life questionnaires, $95 \%$ of patients were satisfied, even though some of them did not achieve complete reduction of the prolapse. The results remained unaltered at the 12-month follow-up. The authors concluded that this technique is a safe method of treatment of third- and fourth-degree hemorrhoids, with no major complications and with satisfactory results. ${ }^{31}$ However, it was a preliminary study with a small number of patients and short follow-up time, thus making it difficult to assess long-term efficacy. Other studies are therefore needed to confirm the results.

\section{THD versus stapled hemorrhoidopexy}

A systematic review evaluated three randomized trials comparing THD to stapled hemorrhoidopexy in the management of hemorrhoidal disease. A total of 150 patients were investigated, 80 THD patients and 70 stapled hemorrhoidopexy patients. THD had success rates slightly higher than those reported for stapled hemorrhoidopexy, but without statistically significant difference. Both techniques were considered equally effective in the management of hemorrhoidal disease ${ }^{32}$. Both groups were similar in terms of operation time, postoperative complications, and recurrence of hemorrhoidal disease. THD was associated with significantly less postoperative pain. The authors concluded that the two procedures are equivalent in terms of symptom relief, recurrence rate, and treatment success.However, those were preliminary trials with small samples, and further studies are still required.

A prospective study compared PPH with THD for the treatment of second- and third-degree hemorrhoids. Patients with fourth-degree hemorrhoids and those with a large external component were excluded. Patients were randomly allocated to THD or PPH, which was decided blindly by the operating surgeon without being aware of the patient's preoperative symptoms. Patients were reassessed at eight weeks and eight months. After three years, patients were reassessed with a telephone interview. A total of 52 patients completed the study. THD patients returned to work earlier than PPH patients. There were no differences in the rate of postoperative complications or readmissions between groups. After three years, the recurrence rate was similar between groups, accounting for three (14\%) THD patients and two (13\%) PPH patients. No differences were observed as for symptom improvement and patient satisfaction between groups ${ }^{8}$.

Another multicenter study comparing THD with PPH for the treatment of third-degree hemorrhoids also showed similar results, concluding that the two techniques are equally effective. THD appears to have a better costeffective ratio and lower pain compared with $\mathrm{PPH}$. Disease recurrence did not differ between the two techniques ${ }^{11}$. 


\section{CONCLUSIONS}

The ideal surgical option for the treatment of hemorrhoids should be able to provide relief of symptoms, produce few complications and have a low recurrence rate. With conventional surgery, whatever the technique or material used, the risk of recurrence is lower, i.e., it is associated with a more definitive treatment. Conversely, patients are faced with more postoperative pain and longer healing time. Despite new surgical options, hemorrhoidectomy remains the treatment of choice and the gold standard for most cases. In this context, an important aspect to be considered by surgeons is the appropriate management of postoperative pain, with local anesthetic infiltration associated with oral analgesics, or even with use of topical muscle relaxants.

With the new techniques, PPH and THD, although less postoperative pain is observed, there is a greater likelihood of recurrence. High rates of late recurrence have dampened enthusiasm for use of PPH. To date, THD has proven superior to $\mathrm{PPH}$, with a lower rate of (especially late) complications and earlier return to normal activities.

Nevertheless, the success of the technique depends on the careful selection of cases. Multicenter studies involving a larger number of patients and long-term results are warranted to more accurately assess this method.

\section{REFERENCES}

1. Andrews BT, Layer GT, Jackson BT, Nicholls RJ. Randomized trial comparing diathermy haemorrhoidectomy with the scissor dissection Milligan-Morgan operation. Dis Colon Rectum 1993; 36: 580-3.

2. Cheetham MJ, Mortensen NJ, Nystrom PO. Persistent pain and faecal urgency after stapled haemorrhoidectomy. Lancet 2000; 356:730-3.

3. Chen JS, You JF. Current Status of Surgical Treatment for HemorrhoidsSystematic Review and Meta-analysis. Chang Gung Med J 2010;33: 488-500.

4. Cirocco WC. Life-threatening sepsis and mortality following stapled haemorrhoidectopexy. Surgery 2008; 143:824-9.

5. Ferguson JA, Mazier WP, Ganchrow MI, Friend WG. The Closed Technique of hemorrhoidectomy. Surgery 1971; 70:480.

6. Galizia G, Lieto E, Castellano P, Pelosio L, Imperatore V, Pigantelli C. Lateral internal sphincterotomy together with haemorrhoidectomy for treatment of haemorrhoids: a randomised prospective study. Eur J Surg 2000; 166: 223-8.

7. Giordano P, Gravante G, Sorge R et al. Long-term Outcomes of stapled haemorrhoidectomy vs. conventional haemorrhoidectomy: a metaanalysis of randomized controlled trials. Arch Surg 2009; 144:266.

8. Giordano P, Nastro P, Davies, Gravante G. Prospective evaluation of stapled haemorrhoidopexy for stage II and III haemorrhoids: threeyear outcomes 2011; 15: 67-73.

9. Giordano P, Overton J, Madeddu F, Zaman S, Gravante G.Transanal haemorrhoidal dearterialization : a systematic review. Dis Colon Rectum 2009; 52(9): 1665-1671.

10. Grigoropoulos P, Kalles V, Papapanagiotou I, Mekras A, Argyrou A, Papageorgiou K, Derian K. Early and Late complications of stapled haemorrhoidopexy: a 6-year experience form a single surgical clinic. Tech Coloproctol 2011; 15(1):579-81.

11. Infantino A, Altomare DF, Bottini C, Bonanno M, Mancini S; THD group of the SICCR(Italian Society of Colorectal Surgery), Yalti T, Giamundo P, Hoch J, El Gaddal A, Pagano C. Prospective randomized multicentre study comparing stapler haemorrhoidopexy with Doppler-guided transanal haemorrhoid dearterialization for thirddegree haemorrhoids. Colorectal Dis 2012; 14(2): 205-11.
12. Jayaraman $\mathrm{S}$, Colquhoun $\mathrm{PH}$, Malthaner RA. Stapled haemorrhoidopexy is associated with a higher long-term recurrence rate of internal haemorrhoids compared with conventional excisional haemorrhoid surgery. Dis Colon Rectum 2007; 50:1297-1305.

13. Jayaraman S, Colquhoun PH, Malthaner RA. Stapled vs. conventional for haemorrhoids. Cochrane Database Systematic Review 2006; CD005393.

14. Jayne DG, Botterill I, Ambrose NS, Brennan TG, Guillou PJ, O Riordain DS. Randomized clinical trial of Ligasure vs. conventional diathermy for disease Haemorrhoidectomy. Br J Surg 2002; 89: 428-32.

15. MacRae HM, McLeod RS. Comparison of hemorrhoidal treatments: a meta-analysis. Can J Surg 1997;40(1):14-17.

16. Milito G, Gargiani M, Cortese F. Randomized trial comparing Ligasure haemorrhoidectomy with the diathermy dissection operation. Tech Coloproctology 2002; 6: 171-5.

17. Molloy RG, Kingsmore D. Life threatening pelvic sepsis after stapled Haemorrhoidectomy. Lancet 2000; 355:810.

18. Nienhuijs S, de Hingh I. Convencional vs. Ligasure hemorrhoidectomy for patients with symptomatic hemorrhoids. Cochrane Database Syst Rev 2009; CD 006761.

19. Nisar PJ, Acheson AG, Neal KR, Scholefield JH. Stapled Haemorrhoidectomy compared with conventional haemorrhoidectomy: Systematic review of randomized controlled trials. Dis colon Rectum 2004; 47: 1837.

20. Pessaux $P$, Lermite $E$, Tuech JJ. Pelvic sepsis after stapled haemorrhoidectomy . J Am Coll Surg 2004; 199: 824-5.

21. Ratto C, Giordano P, Donisi L, Parello A, Litta F, Doglietto GB.Transanal haemorrhoidal dearterialization (THD) for selected fourth-degree haemorrhoids. Tech Coloproctol 2011; 15(2): 191-7.

22. Ratto C, Lorenza D, Parello A, Litta F, Zaccone G, De Simone V. Distal doppler-guided dearterialization is highly effective in treating haemorrhoids by transanal haemorrhoidal dearterialization. Colorectal Dis. 2012 14:e786-9. doi: 10.1111/j.1463-1318.2012.03146.x.

23. Ripetti V, Caricato M, Arullani A. Rectal perforation, retropneumoperitoneum and pneumomediastinum after stapling procedure for prolapsed haemorrhoids: Report of a case and subsequent considerations. Dis Colon Rectum 2002; 45:268-70.

24. Rivadeneira DE, Steele SR, Ternent C, Chalasani S, Buie WD, Rafferty JL. Practice Parameters for the Management of Hemorrhoids (Revised 2010). In Dis Colon Rectum 2011; 54(9): 1059-1064.

25. Sajid MS, Parampali U, Whitehouse P, Sains P, McFall MR, Baig MK. A Systematic review comparing transanal haemorrhoidal dearterialization to stapled haemorrhoidopexy in the management of haemorrhoidal disease. Tech Coloproctol 2012; 16(1): 1-8.

26. Schubert MC, Sridhar S, Schade RR, Wexner SD. What every gastroenterologist needs to know about common anorectal disorders. World J Gastroenterol 2009; 15(26): 3201-3209.

27. Schuurman JP, Borel Rinkes IH, Go PM. Hemorrhoidal artery ligation procedure with or without Doppler transducer in grade II and III hemorrhoidal disease: a blinded randomized clinical trial. Annals of Surgery 2012; 255(5): 840-845.

28. Senagore A, Mazier WP, Luchtefeld MA, MacKeigan JM, Wengert T. Treatment of advanced hemorrhoidal disease: a prospective, randomized comparison of cold scalpel vs. contact Nd: YAG laser. Dis Colon Rectum 1993; 36:1042-9.

29. Tjandra JJ, Chan MK. Systematic review on the procedure for prolapse and haemorrhoids (stapled Hemorrhoidopexy). Dis Colon Rectum 2007; 50:878-892.

30. Walega P, Romaniszyn M, Kenig, Herman R, Nowak W. Dopplerguided hemorrhoid artery ligation with recto-anal-repair modification: functional evaluation and safety assessment of a new minimally invasive method of treatment of advanced hemorrhoidal disease. Scientific World Journal 2012;1-6.

31. Wong LY, Jiang JK, Chang SC. Rectal perforation: a life-threatening complications of stapled haemorrhoidectomy: report of a case. Dis Colon Rectum 2003; 46: 116-7. 